\title{
Effusion Cytomorphology of Rhabdomyosarcoma: A Rare Case of Primary Mediastinal Rhabdomyosarcoma with Superior Vena Cava Obstruction and Bilateral Pleural Effusion
}

\author{
B. Deepthi, Nandayala Rukmangadha, Amit Kumar Chauhan, Aruna Kumari Prayaga \\ Department of Pathology, Sri Venkateswara Institute of Medical Sciences, Tirupati, Andhra Pradesh, India.
}

\section{Corresponding Author: \\ Dr. B. Deepthi \\ Email: drbdeepthi@gmail,com}

This is an Open Access article distributed under the terms of the Creative Commons Attribution License (creativecommons.org/ licenses/by/3.0).

Received Accepted

Published

November 28, 2019

February 11, 2020

February 20, 2020

\begin{abstract}
Background: Primary mediastinal rhabdomyosarcoma (RMS) unassociated with germ cells, teratomatous or malignant epithelial components are extremely rare, tend to have large size, important local invasion at diagnosis, with aggressive behavior and poorer prognosis. Case Report: We present an extremely rare case of primary mediastinal RMS with malignant pleural effusion in a fourteen year old female patient with emphasis on cytological examination of the pleural fluid, diagnostic difficulties and differential diagnosis. Cellular smears showed numerous discretely scattered reactive mesothelial cells admixed with numerous neutrophils and lymphocytes. In addition there was a distinct second population of neoplastic cells essentially singly scattered and occasional dyshesive clusters seen initimately mingled with reactive mesothelial and inflammatory cells. Conclusion: This case elucidates the potential pitfall in identifying the single scattered neoplastic cells from initimate admixture with reactive mesothelial cells and highlights the importance of careful cytomorphologic evaluation with adjunct immunocytochemistry for myogenin to accurately diagnose metastatic RMS in effusion specimens.
\end{abstract}

Keywords: Cytodiagnosis, Germ Cells, Immunohistochemistry, Pleural Effusion, Rhabdomyosarcoma.

\section{Introduction}

Rhabdomyosarcoma (RMS) is the most common soft tissue sarcoma in children and adolescents and accounts for approximately $5 \%$ of all pediatric cancers and $50 \%$ of pediatric soft tissue sarcomas [1-4]. The embryonal and alveolar variants are more commonly seen in children while pleomorphic variant is seen more often in adults [5-7]. Primary mediastinal RMS is extremely rare primary site of origin. To our knowledge only a handful of mediastinal alveolar rhabdomyosarcoma have been reported. The Intergroup RMS study group (IRSG) has described this as an unfavourable site owing to difficulty in surgical resection with propensity to infiltrate vital structures [8-10].
Metastases develop during the course of the disease and are present at the time of diagnosis in about $20 \%$ of cases. Lung is the most common site of metastases in these tumors with other site of distant metastatic involvement include bone marrow (approximately 30\%), bone (30\%), omentum (ascites 16\%), and pleura (13\%) [11]. Experience with cytology of rhabdomyosarcomas (RMS) is largely confined to fine needle aspiration samples and touch imprints. Sarcomas may represent up to $5 \%$ of all malignant effusion specimens [12], malignant effusions are all the more rare in rhabdomyosarcoma patients, and experience with the effusion cytological features of RMS is largely limited [13-15]. Herein we present an extremely rare case of metastatic mediastinal RMS diagnosed 
on cytological examination of the pleural fluid with emphasis on diagnostic difficulties and differential diagnosis.

\section{Case Report}

A fourteen year old female presented with breathlessness and facial puffiness since one month duration. On evaluation, CT chest showed a mass measuring $8 \times 6 \mathrm{~cm}$ occupying the anterior and middle mediastinum, compressing the superior vena cava with bilateral pleural effusion. Laboratory investigations showed hemoglobin 9.9 $\mathrm{g} / \mathrm{dL}, \mathrm{C}$ reactive protein: $60.07 \mathrm{mg} / \mathrm{L}$ (normal $<6$ $\mathrm{mg} / \mathrm{L}$ ), blood urea: $25 \mathrm{mg} / \mathrm{dL}$, serum creatinine: $0.4 \mathrm{mg} / \mathrm{dL}$, serum LDH: $400 \mathrm{IU} / \mathrm{L}(<247 \mathrm{IU} / \mathrm{L})$, Examination of pleural fluid showed albumin: 27 g/dL, glucose: 96 mg/dL, LDH: 519 IU/L, protein: $3.7 \mathrm{~g} / \mathrm{dL}$, ADA: $09 \mathrm{U} / \mathrm{L}$. Serum tumor markers (HCG, CA 125, AFP) were negative. PET CT was suggestive of metabolically active irregular soft tissue density lesion in anterior and middle mediastinum causing compression of superior venae cavae and diffuse involvement of bone marrow. Pleural fluid cytology and CT guided trucut biopsy of the medisatinal mass was suggestive of RMS with malignant effusion.

Hematoxylin and Eosin, PAP and May Grunwald Giemsa preparations of the cytospun pleural fluid material were studied. The smears were cellular and showed numerous discretely scattered reactive mesothelial cells admixed with numerous neutrophils and lymphocytes. In addition there was a distinct second population of neoplastic cells essentially singly scattered and occasional dyshesive clusters seen intimately mingled with reactive mesothelial and inflammatory cells [Fig.1a]. The morphology of these discretely scattered cells were one and a half times larger than the adjacent mesothelial cells exhibiting high NC ratio, nuclear hyperchromasia with open chromatin and occasional ones showing prominent nucleoli [Fig.1b]. The nuclei showed moderate anisocytosis with irregular nuclear contours, some showing striking embryoid/ convoluted multilobulated nuclear configuration [Fig.1c]. Ocassional yet distinct bi and multinucleated neoplastic cells are seen with some displaying prominent intranuclear inclusions [Fig.2a]. Many of the singly scattered and cells within the clusters showed distinct fine cytoplasmic vacuolations [Fig.2b]. The cytoplasm was scant to moderate to abundant with delicate frail pale blue hue and cell membrane knobs and cytoplasmic protrusions [Fig.2c]. There were no distinct cell windows within the cells in clusters. Concurrently we received CT guided tru-cut biopsy from the mediastinal mass displaying small to medium sized cells with hyperchromatic nucleus and scant eosionophilic cytoplasm arranged as clusters, acinar/ rosette pattern [Fig.3a]. With the differential diagnosis of small round cell, tumor IHC was performed. The tumor cells were negative for CK7, LCA, CD99, Fli1, Tdt. They showed strong cytoplasmic positivity to desmin and nuclear positivity with Myf4 [Fig.3b,c]. A diagnosis of mediastinal RMS possibly alveolar subtype with malignant pleural effusion was made. As the patient had SVC compression she underwent palliative radiotherapy and referred to medical oncology with plan to treat RMS stage IV in view of malignant effusion.

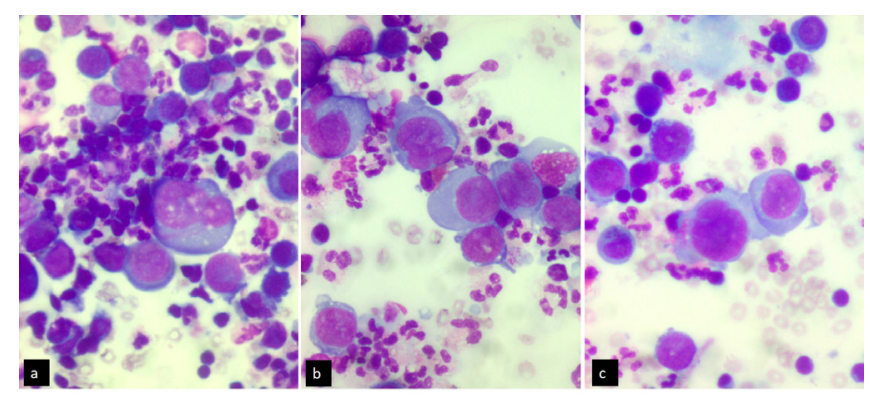

Fig.1:(a): Neoplastic cells intermixed with reactive mesothelial and inflammatory cells. Note the eccentric location of the nuclei of neoplastic cells. (b,c): Loose dyshesive cluster of multilobated/ multinucleated, large, pleomorphic tumor cell with dense cytoplasm along with ocassional discretely scattered small undifferentiated tumor cells. (a, b,c. May Grunwald stain, all images original magnification, ×400). 


\section{Discussion}

RMS is an aggressive sarcoma with skeletal muscle differentiation that primarily affects children and young adults. The most common sites are head and neck (43\%) and trunk (7\%) with rare mediastinal location [16]. The most common primary mediastinal mass lesions include teratoma, malignant lymphoma, Hodgkins disease and germ cell tumors with RMS being a rare cause $[17,18]$. Although thoracic neoplasms may present with pleural effusion, rhabdomyosarcoma can rarely exfoliate into pleural fluid resulting in malignant effusions and cytological diagnosis can be difficult [15,19-22]. There is limited experience elucidating the effusion cytomorphological features of RMS though greater number describes the FNA features. We attempted to describe our findings in this extremely rare case of metastatic mediastinal RMS. With the negative serum tumor markers, the association/ origin of RMS as a part of germ cell tumor is less likely. There are only few cases of primary mediastinal RMS unassociated with germ cell tumor. These tumors behave aggressively, as in our case, it presented with large size, compressing the SVC and bilateral pleural effusion. Hence complete surgical removal was not contemplated owing to large tumor with inaccessibility and malignant efussion with stage IV disease.

The cytomorphology findings of singly scattered round disassociated cells with close intermingling with singly scattered mesothelial cells and dense inflammatory cells can be a potential source of missed diagnosis. There were very occasional loose dyshesive clusters with high NC ratio, nuclear hyperchormasia and distinct cytoplasmic vacuoles. The cytoplasmic vacuolations due to glycogen presence may indicate state of differentiation from the primitive state of RMS. There was no evidence of any characteristic strap cells with cross striations suggestive of typical rhabdomyoblasts. Presence of rounder cells with irregular nuclear contours, multinucleate giant cells, embryoid type convoluted nuclei may be suggestive of alveolar subtype.

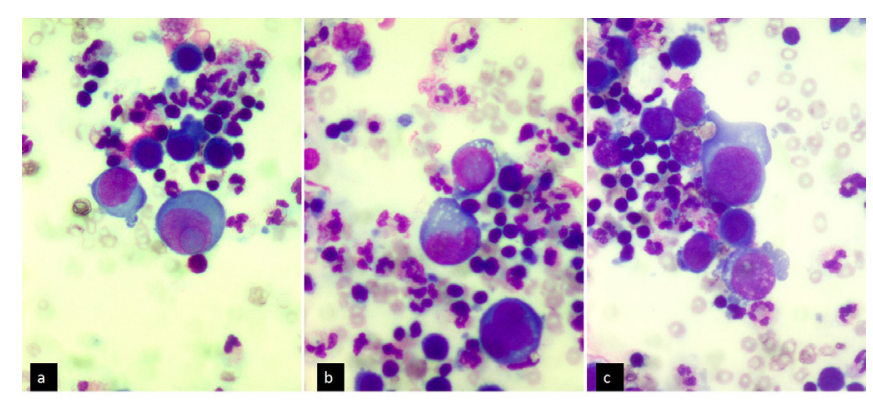

Fig.2:(a,b): Neoplastic cells showing prominent intranuclear inclusions and intracytoplasmic fine vacuolations. (c): Moderate to abundant delicate frail blue cytoplasm with cell membrane knobs and cytoplasmic protrusions (a, b,c. May Grunwald stain, all images original magnification, $\times 400)$.

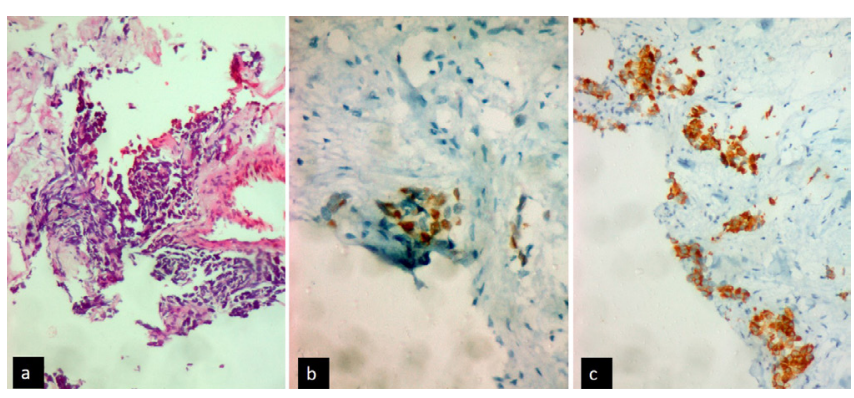

Fig.3:(a): Trucut biopsy shows small foci of lesional cells composed of small to medium sized cells with hyperchromatic nucleus and scant eosionophilic cytoplasm arranged as clusters, acinar/ rosette pattern (H and E, ×100) (b): IHC with Myf4 showing intense nuclear positivity. (c): IHC with desmin showing intense cytoplasmic positivity $(\times 400)$.

Cytological diagnosis of undifferentiated round cell tumors is often problematic using light microscopic assessment alone because of much overlapping morphological features and lack of cytoplasmic maturation. Diagnosis is made by combination of histological findings along with ancillary techniques which include immunocytochemistry/IHC, electron microscopy, cytogenetic and molecular genetic studies. A wide panel of markers are required for confirmation of second non inflammatory-nonmesothelial population and the choice depends on the initial morphological features. The other differential diagnosis to be considered in case of fluid involvement by round cells are Ewings sarcoma/ 
PNET, neuroblastoma, poorly differentiated synovial sarcoma, precursor lymphoblastic lymphoma/leukemia, rhabdoid tumors neuroendocrine carcinoma and other round cell sarcomas.

In our case, the panel of immunostains was based on the suspected second (malignant) cell population and included CK7, LCA, CD99, Fli1, Tdt, desmin, and Myf5. The utility of muscle specific markers are the preferred and mainstay adjuncts in confirmation of RMS which include expression of desmin and myogenic transcription factors like myogenin, MyoD, Myf5 and MRF4. In effusion cytology, desmin immunocytochemistry is of limited value; desmin immunostains are difficult to interpret as background mesothelial cells also exhibit immunoreactivity for desmin. Myogenin has emerged as a sensitive and specific marker of skeletal muscle differentiation with some studies demonstrating higher expression in alveolar subtypes in comparison to embyonal type.

Theunissen et al. [21] reported a case of the cytologic diagnosis of rhabdomyosarcoma in a patient with pleural effusion. They described a Papanicolaou-stained smear of the pleural effusion that showed highly cellular fluid containing isolated and clustered cells with rather scanty cytoplasm and large, round, slightly polymorphous nuclei; the nuclei were accompanied by very large cells with abundant cytoplasm, conspicuous perinuclear clearing, and very prominent nucleoli. Other articles have described the effusion cytomorphologic features of rhabdomyosarcoma as having scattered multinucleated tumor giant cells, eccentric nuclei, dense and opaque cytoplasm, multinucleation, coarse chromatin, and inconspicuous nucleoli. Nelson et al. [22] in their case report highlighted the initial misdiagnosis of the neoplastic cells in pleural fluid with reactive mesothelial cells with later confirmation by IHC with myogenin. Our case had pattern closely resembling the description of the latter.
This case highlights the importance of careful cytomorphologic evaluation with adjunct immunocytochemistry for myogenin can accurately diagnose metastatic RMS in effusion specimens. Myogenic transcription factors like myogenin, MyoD, Myf5 and MRF4 represents a sensitive and specific marker for the workup of RMS in effusion cytology.

Contributors: BD: manuscript writing, literature review and histopathology; NR, AKC: critical inputs into the manuscript and histopathology; AP: literature review, discussion and histopathology. BD will act as a study guarantor. All authors approved the final version of this manuscript and are responsible for all aspects of the study.

Funding: None; Competing interests: None stated.

\section{References}

1. Wexler L, Meyer W, Helman L. Rhabdomyosarcoma and the undifferentiated sarcomas. In: Pizzo P, Poplack D, editors. Principles and practice of pediatric oncology. 5th edn. Philadelphia: Lippincott Williams \& Wilkins. 2006;971-1001.

2. Egas-Bejar D, Huh WW. Rhabdomyosarcoma in adolescent and young adult patients: current perspectives. Adolesc Health Med Ther. 2014;5:115-125.

3. DasguptaR, RodebergDA.Updateonrhabdomyosarcoma. Semin Pediatr Surg. 2012;21:68-78.

4. Ferrari A, Dileo P, Casanova M, Bertulli R, Meazza C, Gandola L, et al. Rhabdomyosarcoma in adults. A retrospective analysis of 171 patients treated at a single institution. Cancer. 2003;98:571-580.

5. Malempati S, Hawkins DS. Rhabdomyosarcoma: review of the Children's Oncology Group (COG) Soft-Tissue Sarcoma Committee experience and rationale for current COG studies. Pediatr Blood Cancer. 2012;59:5-10.

6. Furlong MA, Fanburg-Smith JC. Pleomorphic rhabdomyosarcoma in children: four cases in the pediatric age group. Ann Diagn Pathol. 2001;5:199-206.

7. Furlong MA, Mentzel T, Fanburg-Smith JC. Pleomorphic rhabdomyosarcoma in adults: a clinicopathologic study of 38 cases with emphasis on morphologic variants and recent skeletal muscle-specific markers. Mod Pathol. 2001;14:595-603.

8. Ogilvie CM, Crawford EA, Slotcavage RL, King JJ, Lackman RD, Hartner L, et al. Treatment of adult rhabdomyosarcoma. Am J Clin Oncol. 2010;33:128131.

9. Friedman NB. Tumors of the thymus. J Thorac Cardiovasc Surg. 1967;53:163-182. 
10. Suster S, Moran CA, Koss MN. Rhabdomyosarcoma of anterior mediastinum: Report of four cases unassociated with germ cell, teratomatous, or thymic carcinomatous components. Hum Pathol. 1994;25:349-356.

11. Kocjan G. Fine needle aspiration cytology. Diagnostic dilemmas in fine needle aspiration cytology: Small round cell tumors. In: Schroder G ed. Fine needle aspiration cytology diagnostic principles and dilemmas. Berlin Heidelberg: Springer-Verlag Berlin Heidelberg; 2006.pp.137-8.

12. Chivukula M, Saad R. Metastatic sarcomas, melanoma, and other non-epithlial neoplasms. In: Shidham VB, Atkinson BF, editors. Cytopathologic Diagnosis of Serous Fluids. $1^{\text {st }}$ ed. Philadelphia: Saunders. 2007;p.147156.

13. Hajdu SI, Koss LG. Cytological diagnosis of metastatic myosarcomas. Acta Cytol. 1969;13:545-551.

14. Abadi MA, Zakowski MF. Cytological features of sarcomas in fluids. Cancer. 1998;84:71-76.

15. Thiryayi SA, Rana DN, Roulson J, Crosbie P, Woodhead M, Eyden BP, et al. Diagnosis of alveolar rhabdomyosarcoma in effusion cytology: a diagnostic pitfall. Cytopathology. 2010;21:273-275.

16. Pizzo PA, Poplack DG, Horowitz ME, Hay DM, Kun LE. Solid tumors of childhood. In: DeVita VT, Hellman
S, Rosenberg SA, editors. Cancer: principles and practice of oncology, $4^{\text {th }}$ ed. Philadelphia: J.B. Lippincott Co. 1993;pp. 1738-1791.

17. Grosfeld JL, Skinner MA, Rescorla FJ, West KW, Scherer LR III. Mediastinal tumors in children: experience with 196 cases. Ann Surg Oncol. 1994;1:121-127.

18. Fiorella RM, Lavin M, Dubey S, Kragel PJ. Malignant thymoma in a patient with HIV positivity: a case report with a review of the differential cytologic diagnoses. Diagn Cytopathol. 1997;16:267-269.

19. Thompson KS, Jensen JD, Bhoopalam N, Reyes CV. Pleural effusion cytology of embryonal rhabdomyosarcoma. Diagn Cytopathol. 1997;16:270273.

20. Longatto-Filho A, Bisi H, Bortolan J, Granja NV, Lombardo V. Cytologic diagnosis of metastatic sarcoma in effusions. Acta Cytol. 2003;47:317-318.

21. Theunissen $\mathrm{P}$, Cremers $\mathrm{M}$, van der Meer S, Bot F, Bras J. Cytologic diagnosis of rhabdomyosarcoma in a child with a pleural effusion. A case report. Acta cytol. 2004;48:249-253

22. Nelson AC, Singh C, Pambuccian SE. Cytological diagnosis of metastatic alveolar rhabdomyosarcoma in the ascitic fluid: Report of a case highlighting the diagnostic difficulties. Cytojournal. 2012;9:9. 